\title{
Noise Reduction Effect of Noise Barrier for Shinkansen Based on Y-shaped Structure
}

\section{Kaoru MURATA}

Senior Researcher,

\author{
Kiyoshi NAGAKURA, Dr.
}

Senior Researcher, Noise Analysis G., Envi

\author{
Toshiki KITAGAWA \\ Senior Researcher,
}

\author{
Shin-ichiro TANAKA \\ Researcher,
}

\begin{abstract}
Sound barriers have been widely adopted and installed to reduce noise levels at locations adjacent to Shinkansen tracks. A number of different types of sound barriers with specific configurational features have been developed, but a quantitative evaluation of their advantages has yet to be clarified. In this paper, scale-model experiments were conducted on sound barrier configurations, the positioning of sound-absorbing materials, and a new type sound barrier that was fitted with an acoustic tube array on its upper surface. Sound barriers with effective configurations (Y-shaped sound barriers with absorbing materials and acoustic tube arrays) were proposed based on the experimental results. Furthermore, the authors verified the effectiveness of the proposed barriers by means of field tests with running Shinkansen vehicles.
\end{abstract}

Keywords: sound barrier, Shinkansen, model experiment, field test

\section{Introduction}

Sound barriers have been applied in various transport fields to reduce noise levels. Immediately following the commencement of Tokaido Shinkansen operations, the reduction of trackside noise levels was urged; sound barriers were therefore usually installed along every Shinkansen route. However, in the railway field, studies on the structural improvement of sound barriers have not necessarily made much progress. Particularly in the case of Shinkansen, this has been due to their major sound sources being aerodynamic noise generated by pantographs and other equipment located on the upper part of the vehicles, which could not be prevented by the standard height sound barriers that were already in place ${ }^{1)}$

In this paper, scale-model experiments were conducted into sound barrier configurations, the positioning of sound-absorbing materials, and a new type sound barrier that was fitted with an acoustic tube array on its upper surface. Sound barriers with effective configurations (Y-shaped sound barriers with absorbing materials and acoustic tube arrays) were proposed, based on the experimental results. Furthermore, the authors verified the effectiveness of the proposed barriers by means of field tests with running Shinkansen vehicles.

\section{Experiments with scale models}

\subsection{Outline of experiments}

Models of a viaduct, Shinkansen vehicle and a sound barrier, all to $1 / 20$ scale, were arranged in an anechoic chamber (see Fig. 1). Here, it must be pointed out that the dimensions in this paper are shown to actual scale. The inner surface of the viaduct was made of sound reflective materials to simulate a slab track, and the vehicle model set at an adjacent side or at a remote side. In

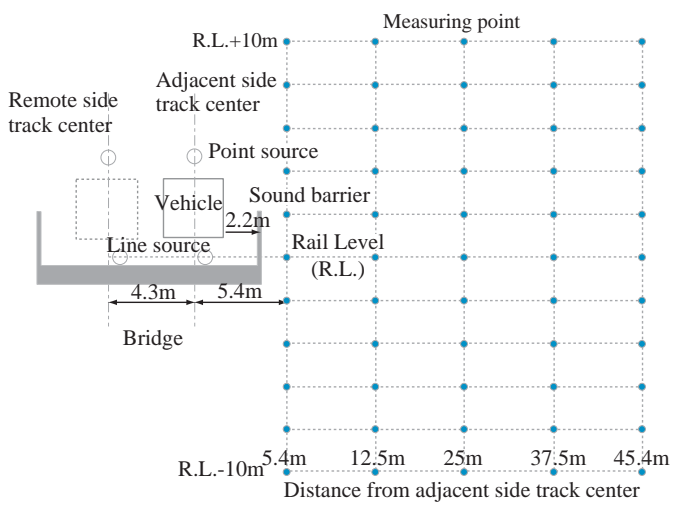

(a) Cross section

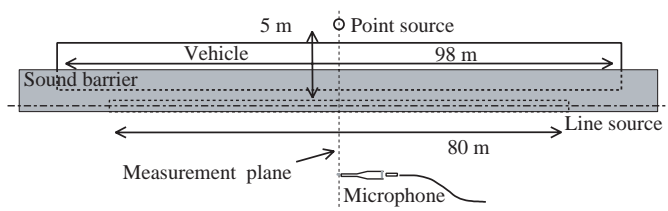

(b) Side view

Fig. 1 Outline of model experiment

this paper, only the results of the adjacent side are described. Two types of sound sources were used to simulate Shinkansen main sound sources ${ }^{1}$ ): a line source to simulate the sound source from the lower part of the vehicle, which is termed the "lower part noise", and a point source to simulate the pantograph noise. Experiments were carried out independently on each sound source.

The measuring points were set on a lattice grid in a plane perpendicular to the rail track and distributed in the range from $10 \mathrm{~m}$ below the rail level (R.L.) to $10 \mathrm{~m}$ above and from $5.4 \mathrm{~m}$ to $45.4 \mathrm{~m}$ horizontally from the center of the adjacent side track. 


\subsection{Configuration of sound barrier}

In the experiments, several types of sound barriers were tested with regard to: (1) sound barrier configuration; (2) the positioning of the sound-absorbing materials; and (3) a new-type sound barrier that was fitted with acoustic tube arrays arranged on its upper surface. Figure 2 shows some of the cross-sectional configurations of the sound barriers used in the experiments. The sizes of the sound barriers were standardized as follows: (1) The height of each sound barrier was $3 \mathrm{~m}$ above R.L.; and (2) the horizontal length of the overhung section on the top of the sound barriers was $1 \mathrm{~m}$. A straight-type barrier 2 $\mathrm{m}$ in height was also tested for comparison with the results of the field test given in Chapter 3. The detailed features of the sound-absorbing materials and acoustic tube arrays will be referred to in Sections 2.4.2 and 2.4.3.

$\begin{array}{lll}\begin{array}{lll}\text { (a) Straight } \\ \text { type }\end{array} & \text { (b) Inverted-L } & \text { (c) Inward inclined (d) Outward inclined } \\ \text { type } & \text { type }\end{array}$

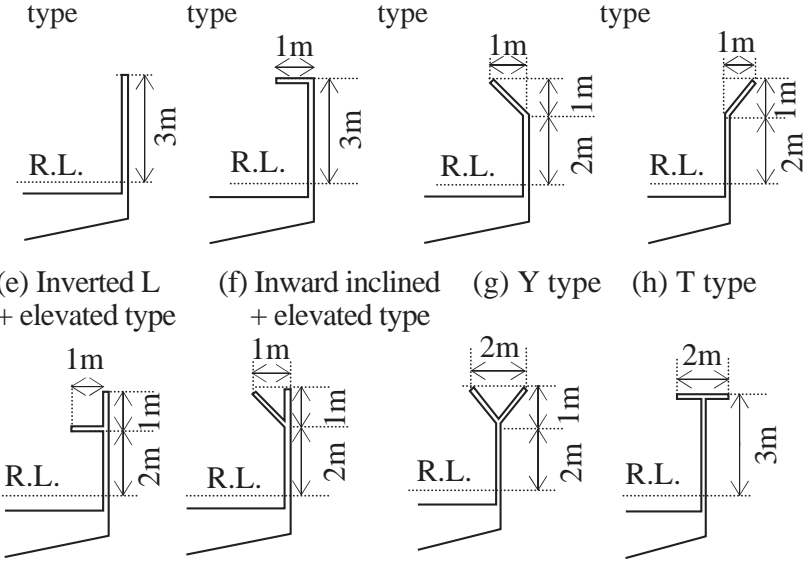

Fig. 2 Cross-sectionsl configurations of sound barriers used in model experiment

\subsection{Analysis method}

The measured sound pressure level (SPL) data were analyzed with an FFT analyzer. The analyzed frequency range was in $2,000 \mathrm{~Hz}$ to $100,000 \mathrm{~Hz}$ band to the model scale, which corresponds to an actual frequency range of between $100 \mathrm{~Hz}$ to $5,000 \mathrm{~Hz}$ band. The $S P L$ measured in the scale-model experiments can be converted to the noise level of real field tests by the following procedure.

(1) Calculate the converted frequency, $f$, the distance between the sources and the measuring points, $r$, and 1/ 3 octave band $S P L, L(f, r)$, by using the acoustic similarity law, which is summarized by Equations (1) to (3).

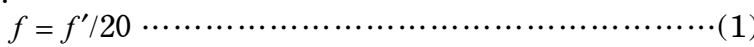

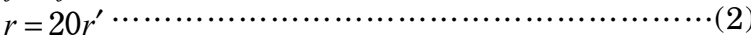

$$
\begin{aligned}
& L(f, r)=L^{\prime}\left(f^{\prime}, r^{\prime}\right)
\end{aligned}
$$

In this case the primed values are those in the scale-model experiments.

(2) Correct the difference in frequency spectrum between the sound sources used in the experiment and the real Shinkansen sound source. Here the frequency spectrum data when a Shinkansen vehicle is running at a speed of $275 \mathrm{~km} / \mathrm{h}$ on a slab track was used as the frequency spectrum of the real Shinkansen sound source ${ }^{1)}$.

(3) Calculate the overall level as the sum of $1 / 3$ octave band $S P L$ from $100 \mathrm{~Hz}$ to $5,000 \mathrm{~Hz}$.

However, the results achieved by this procedure correspond to the noise levels of a train set $80 \mathrm{~m}$ in length for the line noise source, and the noise level corresponding to a single pantograph device for the point noise source. The Shinkansen train set that we are concerned with consists of eight cars with a total length of $200 \mathrm{~m}$, each car equipped with two pantographs $50 \mathrm{~m}$ apart. The wayside noise level when the Shinkansen train set runs should be estimated by adding correcting terms $\Delta_{R}$, denoted in Equation (4) to the lower part noise, and $\Delta_{P}$ denoted in Equation (5) to the pantograph noise, on the assumption that the lower part noise can be approximated by an omnidirectional finite line source and the pantograph noise by omnidirectional point sources ${ }^{2)}$.

$$
\begin{aligned}
& \Delta_{R}=10 \log _{10}\left(\frac{2}{r_{R}} \tan ^{-1}\left[\frac{200}{2 r_{R}}\right]\right)-10 \log _{10}\left(\frac{2}{r_{R}} \tan ^{-1}\left[\frac{80}{2 r_{R}}\right]\right) \cdots \cdots(4) \\
& \Delta_{P}=10 \log _{10}\left(\frac{1}{r_{p}^{2}}+\frac{1}{\left(r_{P}+50\right)^{2}}\right)-10 \log _{10}\left(\frac{1}{r_{p}^{2}}\right) \cdots \cdots \cdots \cdots \cdots \cdots(5)
\end{aligned}
$$

Here $r_{R}$ is the distance between the measuring points and lower part noise sources and $r_{P}$ is that between the measuring points and the pantograph noise sources.

\subsection{Experimental results}

\subsubsection{Effects with respect to sound barrier configuration}

Figure 3 shows contour maps of the lower part noise level and pantograph noise level obtained by experiment with a straight-type sound barrier $3 \mathrm{~m}$ above R.L. in height. For the lower part noise, the noise level at positions above the height of the sound barrier was intense because soundproofing with the sound barrier was not expected. Furthermore, there was an area of particularly high noise levels along a line connecting the body of the vehicle to the upper edge of the barrier, which was prob-

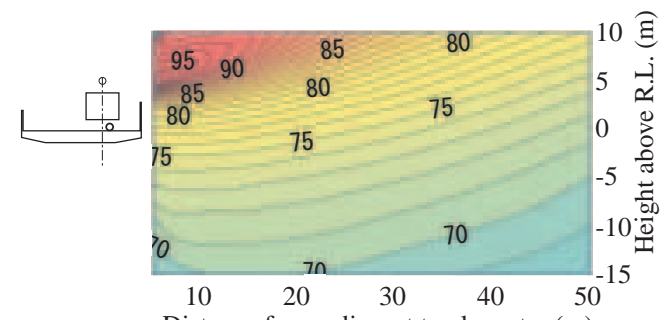

Distance from adjacent track center (m)

(a) Line source on lower part

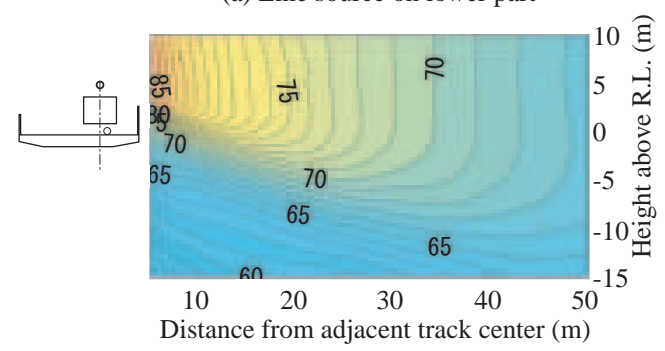

(b) Point source on upper part

Fig. 3 Experimental results of straight type sound barrier 
ably due to the multiple reflections at the sound barrier and the surface of the vehicle. In the case of pantograph noise, the contour line is bent in a line connecting the pantograph with the upper edge of the sound barrier, which means that the effect of the sound barrier largely varies depending on whether or not the pantograph was visible from the measuring point.

Table 1 shows the results of the differences in noise level between the straight-type sound barrier and other types, as measured at a point $25 \mathrm{~m}$ away from the adjacent track and $1.2 \mathrm{~m}$ above ground level at the site (which is termed a "standard point"). A positive value denotes that it is more effective than the straight type. The results are as follows:

(a) Effects on lower part noise:

The Y type, the T type, the inward inclined + elevated type and the inverted-L type are more effective in comparison with the straight-type in terms of noise reduction by more than $3 \mathrm{~dB}$ at the standard point. As characteristics common to the sound barriers as stated above, the phenomenon known as double diffraction occurs at two locations upon the sound transmission to the standard point. Of these, the Y type is the most effective.

(b) Effects on pantograph noise:

Although the outward-inclined type, the $\mathrm{Y}$ type and the $\mathrm{T}$ type are all effective in reducing the noise level by $2 \mathrm{~dB}-3 \mathrm{~dB}$, other types of sound barriers are similar to the straight type in terms of noise reduction. All effective configurations were characterized by overhung outside portions, which means that it is an essential factor for pantograph noise reduction whether the noise source is visible from the measuring point or not.

As a result of the scale-model experiments, the most effective Shinkansen sound barrier configuration is the $\mathrm{Y}$ type. Figure 4 shows contour maps for the differences in noise levels between the Y- and straight-type sound barriers. The positive values denote that the effect of the $\mathrm{Y}$ type is higher than that of straight type. In the case of lower part noise, a high degree of noise reduction is obtained at the area along a line connecting the vehicle with the upper edge of the sound barrier and at the area adjacent to the lower part of the viaduct. The former is due to the effect of the inward inclined part confining the multiple reflective sound inside the barrier. On the other hand, the latter is doubly diffracted at the edges, so large attenuation is ensured in comparison with the straight type. For pantograph noise, a highly effective area is found along a line connecting the sound source and the

Table 1 Difference of effectiveness by the configurations of noise barrier

\begin{tabular}{|l|r|r|r|}
\hline \multicolumn{1}{|c|}{ Type of sound barrier } & $\begin{array}{l}\text { Lower part } \\
\text { noise }\end{array}$ & $\begin{array}{l}\text { Pantograph } \\
\text { noise }\end{array}$ & Total noise \\
\hline Inverted-L type & $3.4 \mathrm{~dB}$ & $-0.5 \mathrm{~dB}$ & $1.8 \mathrm{~dB}$ \\
\hline Inward inclined type & $0.9 \mathrm{~dB}$ & $-2.3 \mathrm{~dB}$ & $-0.3 \mathrm{~dB}$ \\
\hline Outward inclined type & $1.6 \mathrm{~dB}$ & $2.7 \mathrm{~dB}$ & $1.9 \mathrm{~dB}$ \\
\hline Inverted L + elevated type & $2.2 \mathrm{~dB}$ & $0.5 \mathrm{~dB}$ & $1.4 \mathrm{~dB}$ \\
\hline Inward inclined + elevated type & $4.6 \mathrm{~dB}$ & $0.5 \mathrm{~dB}$ & $2.6 \mathrm{~dB}$ \\
\hline Y type & $6.3 \mathrm{~dB}$ & $3.5 \mathrm{~dB}$ & $5.2 \mathrm{~dB}$ \\
\hline T type & $4.5 \mathrm{~dB}$ & $2.5 \mathrm{~dB}$ & $3.8 \mathrm{~dB}$ \\
\hline
\end{tabular}

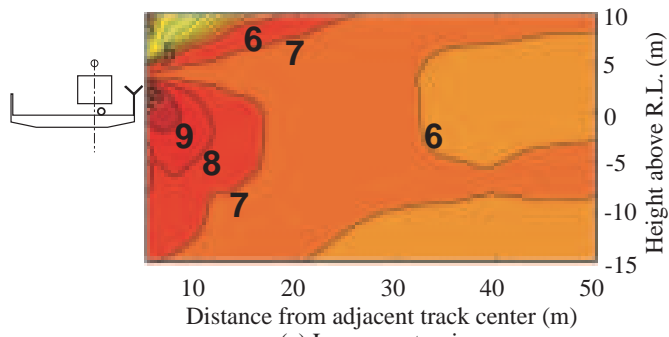

(a) Lower part noise

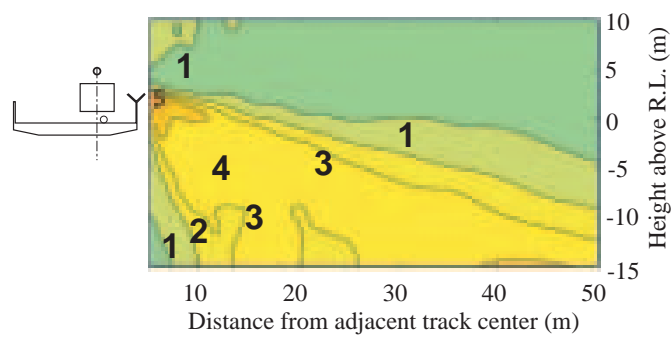

(b) Pantograph noise

\section{Fig. 4 Difference in the noise level of $Y$ type and straight type}

outside overhung edge due to its pantograph noise screening effect.

\subsubsection{Positioning of sound-absorbing materials}

An experiment was performed with regard to the positioning of sound-absorbing materials on the sound barrier. In the experiment, there were four different sound barrier configurations, which are shown in Table 2 with the positions of the sound-absorbing materials. For the purposes of the examination, in which only the lower part noise was tested, we used sponge-like materials $5 \mathrm{~mm}$ in thickness as sound-absorbing materials ${ }^{1)}$. The sound absorption coefficient of the materials was about 0.8 at $20 \mathrm{kHz}(1 \mathrm{kHz} \text { in real scale })^{3)}$.

Figure 5 shows the effect of sound-absorbing materi-

Table 2 Effects of sound barrier with respect to positioning of sound-absorbing materials

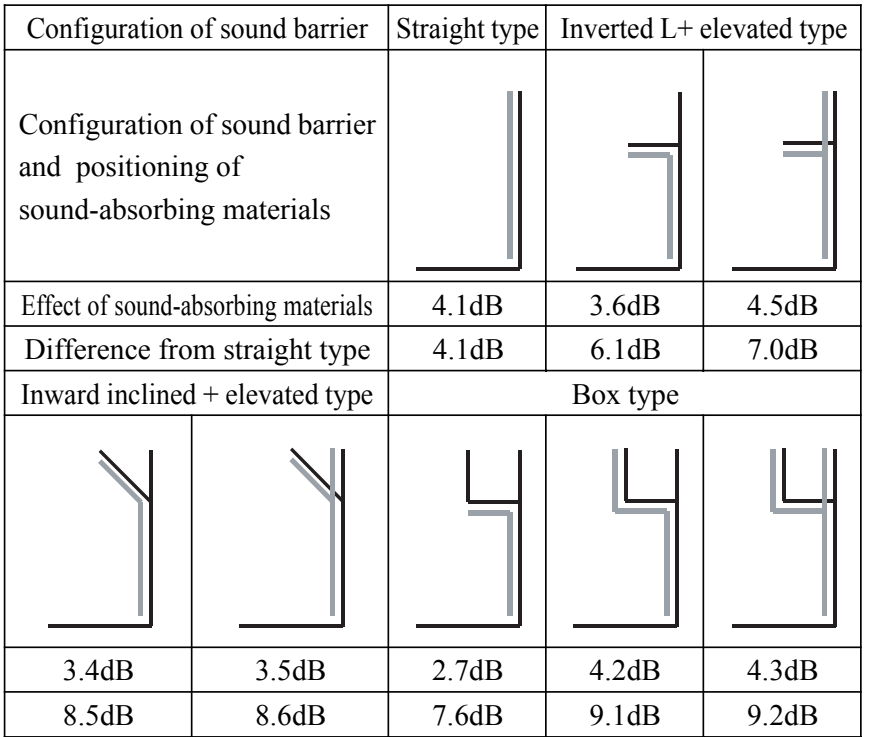




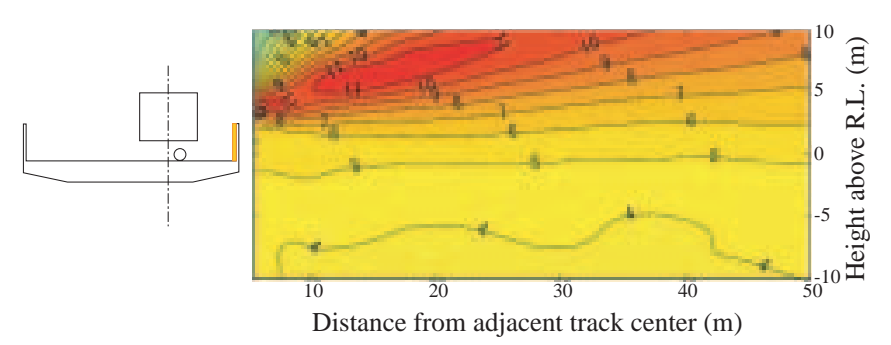

Fig. 5 Effect of sound-absorbing materials on straighttype sound barrier

als on the straight-type sound barrier. The effect of the sound-absorbing materials is conspicuous in the area along a line connecting the body of the vehicle with the upper edge of the barrier. This area corresponds to the direction to which multiple reflective sounds are radiated. Thus, it is concluded that the sound-absorbing materials serves to reduce the multiple reflective sound.

Table 2 also summarizes the effects of the sound-absorbing materials at the standard point. The noise-reduction levels are more pronounced as the area of the sound-absorbing materials increases. However, soundabsorbing materials placed inside a sound barrier tip are barely effective.

\subsubsection{Acoustic tube array on Y-type sound barrier}

In general, the effect of sound-absorbing materials is limited to the high-frequency range (approximately $1 \mathrm{kHz}$ or more). We made an attempt for a measure using an array of acoustic tubes placed on the upper surface of the Y-type sound barrier to reduce low-frequency noise. The principle of this measure is to take advantage of the characteristics at the opening of an acoustic tube, whereby the sound pressure decreases much less when a $1 / 4$ wavelength coincides with the length of the tube ${ }^{4)}$. Therefore,

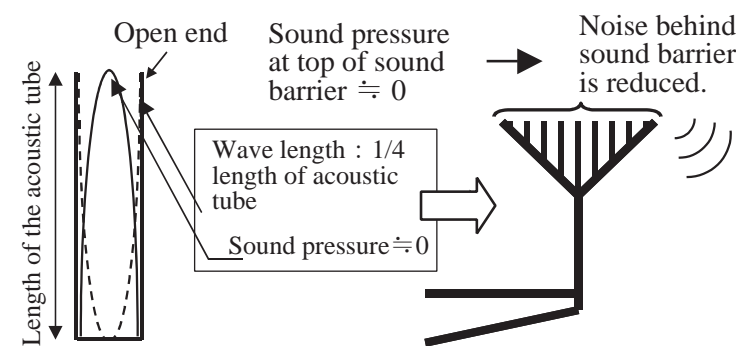

Fig. 6 Principle of acoustic tubes

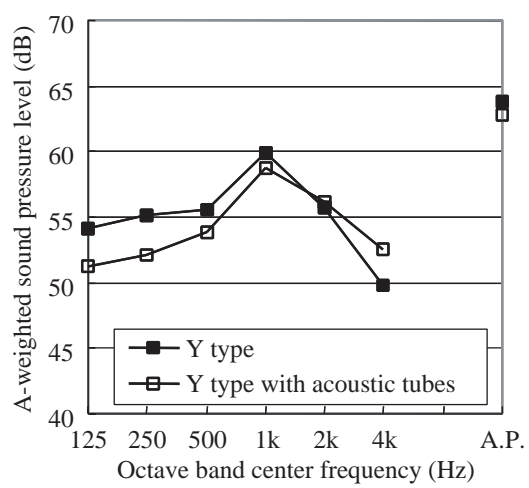

Fig. 7 Effect of the acoustic tubes on lower part noise provided that tubes of various lengths were arranged on the upper surface, the sound pressure on the edge would decrease over a wide frequency range. Figure 6 shows the principle of this measure. In the experiment, many tubes between $0.1 \mathrm{~m}$ and $1 \mathrm{~m}$ in length were arranged on the upper surface of the Y-type sound barrier, the depth of which was $1 \mathrm{~m}$. In this case, an $S P L$ reduction at frequencies from $80 \mathrm{~Hz}$ to $800 \mathrm{~Hz}$ was expected.

Figure 7 shows the experimental result that the acoustic tube arrays could reduce the $S P L$ at intended frequencies. Since this countermeasure can be combined with the Y-type sound barrier which has a highly effective configuration, it is expected to derive a large effect to reduce the wayside noise of the Shinkansen track.

\section{Field test}

\subsection{Outline of the field test}

We temporarily installed a Y-shaped sound barrier with sound-absorbing materials and acoustic tube arrays at a Shinkansen viaduct and verified the noise-reduction effects in a field test. Figure 8 shows the overview of the Y-shaped sound barrier, which was about $30 \mathrm{~m}$ in length, and Fig. 9 details the sound barrier configurations that were tested. Glass wool panels were used for sound-ab-

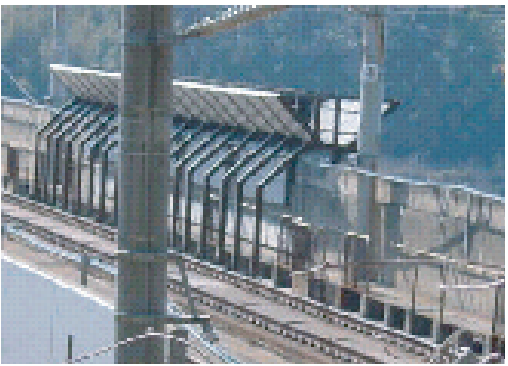

Fig. 8 Overview of Y-shaped sound barrier

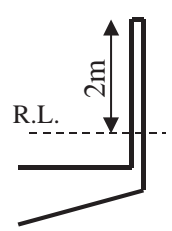

Case 1 Straight type

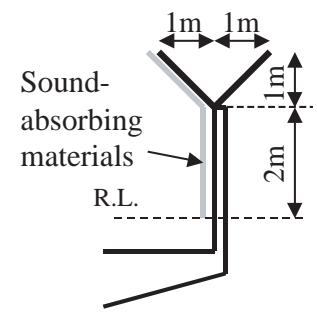

Case 3 Y-shaped type

+ Sound-absorbing materials

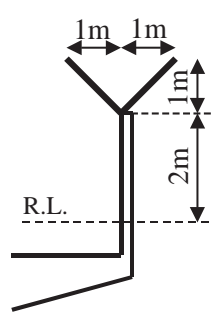

Case 2 Y-shaped type

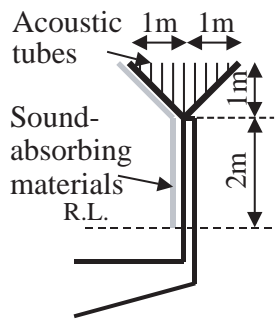

Case 4 Y-shaped type

+ Sound-absorbing materials + Acoustic tubes
Fig. 9 Sound barrier configurations in the field test 


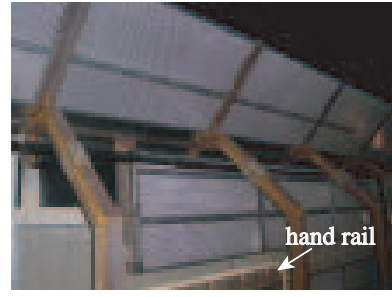

(a) Sound-absorbing materials

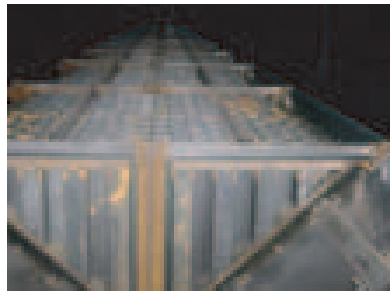

(b) Acoustic tubes
Fig. 10 Installation of sound-absorbing materials and acoustic tubes

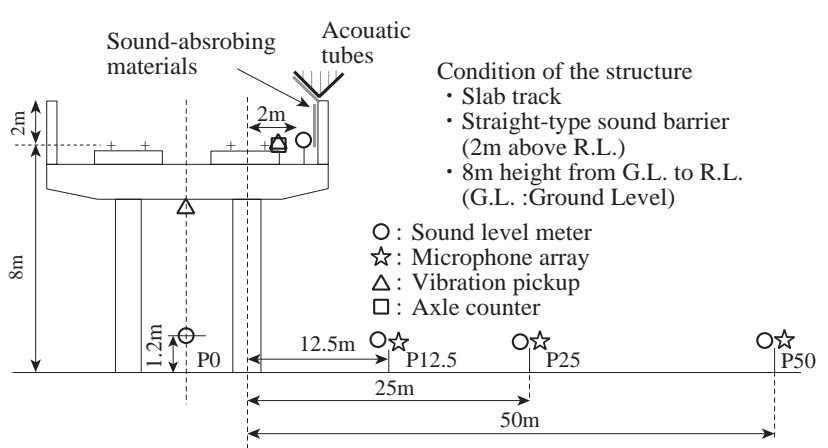

Fig. 11 Measurement configuration in the field test

sorbing materials. These were installed on the inner side of the barrier and divided into two parts, at heights of 0 $-0.5 \mathrm{~m}$ and $0.9 \mathrm{~m}-2.1 \mathrm{~m}$ from the R.L., in order to avoid the handrail (see Fig. 10). The acoustic tubes were $0.1 \mathrm{~m}$ by $0.1 \mathrm{~m}$ rectangular steel pipes and were bound into a 2 $\mathrm{m}$ by $2 \mathrm{~m}$ box unit. The box units were welded to the inside of Y-shaped sound barrier for a length of $20 \mathrm{~m}$, except about $5 \mathrm{~m}$ from the both edges. The construction of the sound-absorbing materials and the acoustic tube array inside the Y-shaped sound barrier is shown in Fig. 10.

The conditions of the field test are shown in Fig. 11. A rail vibration, noise levels in the vicinity of the vehicle and a train velocity were measured on the viaduct. The noise level was measured on the ground beside the track by sound-level meters and linear microphone arrays ${ }^{5)}$ at points $12.5 \mathrm{~m}, 25 \mathrm{~m}$ and $50 \mathrm{~m}$ away from the center of the adjacent track. The length of the temporary sound barrier was so short that the data measured by the sound level meters might have been influenced by diffraction. Therefore, the results from the microphone arrays were mainly used for the evaluation. The noise level under the viaduct and the vibration of the back side of the viaduct were also measured to evaluate concrete bridge structure noise.

Using these field test results, the effect of the Yshaped sound barrier with sound-absorbing materials and acoustic tube arrays could be evaluated.

\subsection{Field test results}

Figure 12 shows an example of the time history of the $S P L$ measured with the microphone array. $L_{P}$ denotes a peak level corresponding to the pantograph noise and $L_{Q}$ denotes corresponding to the rolling noise, the aerodynamic noise from the upper parts of the vehicle and the concrete bridge structure noise.

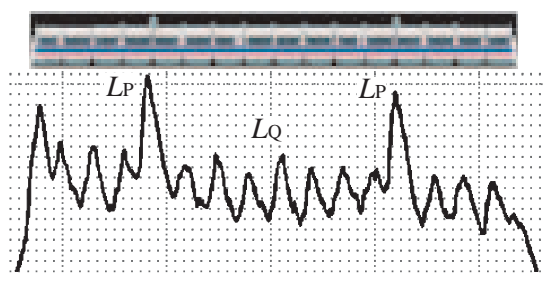

Fig. 12 Example of time history of sound pressure level measured with microphone array

Figure 13 shows the dependence on the train velocity of $L_{Q}$ at P25 and P50, and $L_{P}$ at P25 in each case. The reduction effect for $L_{O}$ in Cases $2-4$ relative to Case 1 at $\mathrm{P} 25$ is about $1.5 \mathrm{~dB}-2.5 \mathrm{~dB}$, which is much smaller than the reduction of the lower part noise in the model

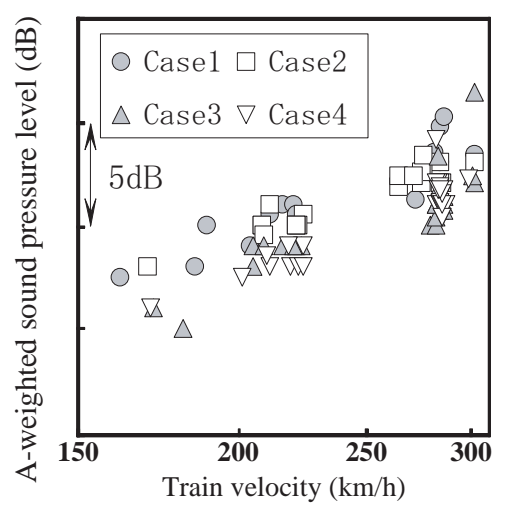

(a) $L_{Q}$ at P25 (25 m away from adjacent track)

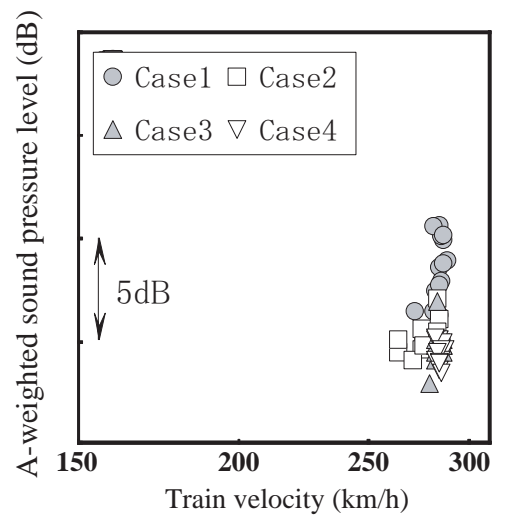

(b) $L_{Q}$ at P50 (50 $\mathrm{m}$ away from adjacent track)

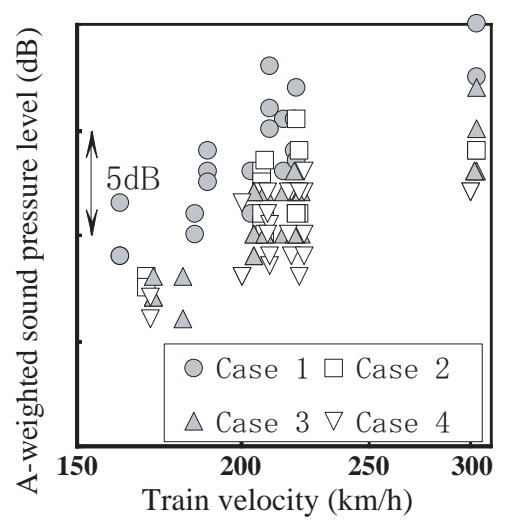

(c) $L_{P}$ at P25 (25m away from adjacent track)

Fig. 13 Peak levels measured with microphone arrays in each condition 
experiment (See Fig. 13(a)). This is probably due to the effect of the concrete bridge structure noise. According to the prediction model of the wayside noise level of Shinkansen ${ }^{6}$, rolling noise in Case 1 is estimated to be greater than the aerodynamic noise from the upper parts of the vehicle by about $6 \mathrm{~dB}$ and the concrete bridge structure noise by about $8 \mathrm{~dB}$. However, the measured data at P0 suggest that the power level of the concrete bridge structure noise at the site is greater than the ordinary one determined in the prediction model by more than $5 \mathrm{~dB}$. As a result, it was estimated that about $50 \%$ of $L_{Q}$ at P25 was the concrete bridge structure noise in Case 1 and about $75 \%$ in Case 4 , according to the distance attenuation ${ }^{5)}$ from the sound pressure level at $\mathrm{P} 0$. On the other hand, at P50 where the concrete bridge structure noise is considerably attenuated, the reduction of $L_{Q}$ relative to Case 1 was $3.5 \mathrm{~dB}$ in Case 2, $4 \mathrm{~dB}$ in Case 3 and $4.5 \mathrm{~dB}$ in Case 4 (See Fig. 13(b)). These values denote minimum reduction effect for the lower part noise because the influence of the concrete bridge structure noise was not removed completely even at P50. From Fig. 4, it was confirmed that the effect of the Y-shaped sound barrier for the lower part noise at P25 is almost the same as that at P50, thus the values mentioned above also can be expected at P25. Figure 13(c) shows that the reduction effect for $L_{P}$ in Cases $2-4$ relative to Case 1 at P25 is about $5 \mathrm{~dB}$.

Table 3 shows the effects of a Y-shaped sound barrier on a straight-type sound barrier $2 \mathrm{~m}$ in height (Case 1). In Table 3, the data marked "*" denote those measured at P50, the other data at P25. The results of the model experiment are also shown in Table 3 for comparison with those from the field test. Table 3 shows that the results of the field test and those of the model experiment are in good agreement about $L_{P}$ and that the reduction of $L_{Q}$ in the field test is a little smaller than that in the model experiment but the their tendency almost agrees.

Figure 14 shows the results of $1 / 3$-octave band spec-

Table 3 Effect of Y-shaped sound barrier to $2 \mathrm{~m}$ straight type sound barrier (Case 1) (Train velocity : $275 \mathrm{~km} / \mathrm{h}$ )

\begin{tabular}{|c|c|c|c|}
\hline \multicolumn{2}{|c|}{} & $L_{P}$ & $L_{Q}$ \\
\hline Model experiment & Case 2 & $6.5 \mathrm{~dB}$ & $6.2 \mathrm{~dB}^{*}$ \\
\hline \multirow{3}{*}{ Field test } & Case 2 & $5 \mathrm{~dB}$ & $3.5 \mathrm{~dB}^{*}$ \\
\cline { 2 - 4 } & Case 3 & $5 \mathrm{~dB}$ & $4 \mathrm{~dB}^{*}$ \\
\cline { 2 - 4 } & Case 4 & $5 \mathrm{~dB}$ & $4.5 \mathrm{~dB}^{*}$ \\
\hline
\end{tabular}

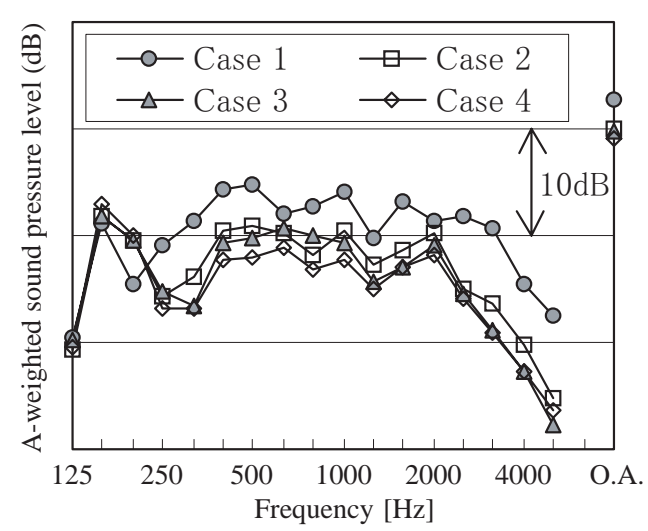

Fig. 14 1/3-octave band spectra of $L_{Q}$ at the point of P50 (Train velocity : $285 \mathrm{~km} / \mathrm{h}$ ) tra of $L_{Q}$ in each case at P50 for the detailed verification of the sound-absorbing materials and the acoustic tube arrays. It was found that the measured data in Case 2 were smaller to that in Case 1 in all frequency ranges. Furthermore it is found that the data in Case 3 are smaller than that in Case 2 at high frequency ranges, and that the data in Case 4 are smaller than that in Case 2 at low frequency ranges. Therefore, these countermeasures are effective at the targeted frequency ranges from the result of the field test, as is the case in the model experiment, as shown in section 2.4 .

\section{Conclusions}

The acoustic experiment with a $1 / 20$ scale model was performed concerning sound barrier configuration, the positioning of sound-absorbing materials and acoustic tube arrays arranged on the upper edge of a Y-type sound barrier. According to the results of the model experiment, the field test was performed at the wayside of Shinkansen when a Y-shaped sound barrier with sound-absorbing materials and acoustic tube arrays was temporarily installed on the viaduct. The following conclusions are obtained from these results.

(1) The Y type is the most effective configuration for a Shinkansen sound barrier, as it has the effect of confining the multiple reflective sounds between the vehicle surface and sound barrier and the double diffraction of the propagated sound wave at the branch edges for lower part noise and has the effect of screening the pantograph noise.

(2) Sound-absorbing materials are effective for reducing multiple reflective noises. The more sound-absorbing materials are in place, the more effective the wayside noise reduction can be. It is especially effective when the sound-absorbing materials are extended near the top of the sound barriers. However, sound-absorbing material is less effective at a location inside the sound barrier tip.

(3) By fitting acoustic tube arrays on the upper surface of the Y-type sound barrier it is possible to decrease lower frequency noise levels, to which it is difficult to decrease with sound-absorbing materials alone.

(4) The reduction of the lower part noise in the field test was a little less than that in the model experiment, but their tendency almost agrees. The results of the field test and those of the model experiment are in good agreement with regard to pantograph noise.

\section{References}

1) Kitagawa, T., "Research on the Effect of Railway Noise Barrier," RTRI Report, Vol. 14, No. 9, pp. $11-16$, 2000.

2) Nagakura, K. and Kitagawa, T., "Study on Effective Shapes of Sound Barriers for Shinkansen," RTRI Report, Vol. 16, No. 12, pp. $17-22,2002$.

3) Ogata, S., "The Experimental Investigation for the Sound Absorptive Coefficient of the Sound Absorption Materials in Scale Model Experiment for Rail- 
way Noise," Proceedings of Symposium in Acoustical Society of Japan, 2000 (in Japanese).

4) Chul-hwan, Kim and Fujiwara, K., "Sound Shielding Efficiency of T-shaped Noise Barrier with Tube Array on the Top Surface" The Journal of the Acoustical Society of Japan, Vol. 54, No. 3, pp. 179 - 189, 1998 (in Japanese).
5) Nagakura, K., "The Methods of Analyzing Shinkansen Noise," QR of RTRI, Vol. 37, No. 4, pp. $210-215$, 1996.

6) Nagakura, K., and Zenda, Y., "Prediction Model of Wayside Noise Level of Shinkansen," RTRI Report, Vol. 14, No. 9, pp. 5-10, 2000. 